\title{
The efficiency of a risk reduction program for debris-flow disasters - a case study of the Songhe community in Taiwan
}

\author{
S. C. Chen ${ }^{1}$, C. Y. Wu ${ }^{1}$, and B. T. Huang ${ }^{2}$ \\ ${ }^{1}$ Department of Soil and Water Conservation, National Chung-Hsing University, Taichung 40227, Taiwan \\ ${ }^{2}$ Taitung Branch, Soil and Water Conservation Bureau, Taitung 95055, Taiwan
}

Received: 22 March 2010 - Revised: 18 June 2010 - Accepted: 7 July 2010 - Published: 16 July 2010

\begin{abstract}
A risk reduction program was developed after debris-flow disaster analysis is conducted using mitigation structures, evacuation measures and community restrained expansion strategy. The risk assessment method delineates hazard zones and analyzes vulnerability and the resilient capacity of an affected area, allowing the prediction of losses of properties and lives, and the corresponding risk. It can also be used to evaluate performance of a risk reduction program. The proposed method was applied to the Songhe community as a case study to assess debris-flow risk and performance of reduction programs consisting of mitigation structures, evacuation measures and a restrained expansion strategy. Total annual risk decreased to $\$ 0.01$ million from $\$ 0.72$ million for the No. 1 Torrent and to $\$ 0.36$ million from $\$ 1.22$ million for the No. 2 Torrent after mitigation structures were installed, and evacuation measures were implemented based on restrained expansion. Although mitigation structures are costly, they can reduce the size of hazard zones. Delimitating the Designated Soil and Water Conservation Area restrains community expansion and decreases possible losses. Although evacuation measures cannot reduce the size of hazard zones, they effectively increase the resilient capacity of residents. The benefit-cost ratio for mitigation structures exceeds 1.0 for both torrents with an average of 3.87; the benefit-cost ratio for evacuation measures is markedly greater than 1.0. Combining mitigation structures and evacuation measures increases the total benefit with a benefit-cost ratio of 4.38. Analytical results showed that the risk reduction program is cost-effective.
\end{abstract}

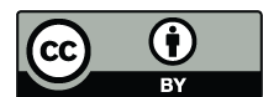

Correspondence to: $\mathrm{C}$. Y. Wu (d9442006@mail.nchu.edu.tw)

\section{Introduction}

Due to its steep topography, fragile geology, seismic activity, and rapid development in mountainous regions, Taiwan is often affected by debris flows. On 21 September 1999, a strong earthquake $\left(M_{\mathrm{L}}=7.3\right)$ with an epicenter in Chichi devastated Central Taiwan and triggered numerous landslides (Chen and Wu, 2006). After the earthquake, the susceptibility of the affected areas to debris flows increased, as heavy rainfall during typhoons or storms causes large landslides of loosened soil (Wu and Chen, 2009). Although most debris flows occur in mountainous regions, they also pose a serious threat to foothill or alluvial fan communities and often result in loss of life and property damage. Due to the uncertainties associated with natural disasters, implementation of risk reduction programs before disasters occur is necessary to minimize losses. In this study, we discuss the risk reduction program consisting of mitigation structures, evacuation measures and a restrained expansion strategy. The objectives of installing engineered mitigation structures are to protect residents and their properties from debris flows and to reduce the size of hazard zones (i.e., deposition zones). The objectives of implementing evacuation measures are to increase the resilient capacity of residents and to decrease loss of life. The restrained expansion strategy indicates that the buildable land in hazardous areas cannot be developed as buildings; instead, it can be used as farmlands. In summary, the objectives of delimiting the Designated Soil and Water Conservation Area are to restrain community expansion and to avoid the possible losses that can increase as the community develops. Risk analyses that account for the inherent uncertainty of debris flows and cost-benefit analyses are required to prioritize prevention tasks in reduction programs. To satisfy this requirement, this work presents a risk analysis method and then applies it to debris flows.

Published by Copernicus Publications on behalf of the European Geosciences Union. 
Risk can be defined as the expected number of lives lost, persons injured, damage to property, and disruption of economic activity due to a natural phenomenon for a given area within a specified period (United Nations, Department of $\mathrm{Hu}-$ manitarian Affairs, 1991). Mathematically, risk can be considered as the product of the probability of occurrence and expected loss (Tobin and Montz, 1997). Deyle et al. (1998) argued that risk has two measurable components: (1) the magnitude of harm that may result and (2) the likelihood or probability of harm occurring at any location within any specified period. According to the ISDR (2002), risk can be represented by a function for naturally induced hazards, corresponding vulnerability and capacity. The function incorporates resilient capacity as a component to account for risk reduction potential via proper management techniques such as educating residents about disaster prevention and implementing evacuation drills.

Defining risk level is important for prioritizing disaster prevention tasks and providing a reference for setting the goals of risk management programs. Various methods have been proposed to determine risk level. Liu and Lei '(2003) assessed the regional hazard for debris flows based on gully density, mean annual rainfall, and the percentage of cultivated land on steep slopes. They also estimated vulnerability based on fixed assets, gross domestic product, land resources, and population density as well as inhabitant age, education level and wealth. Although this method is a reasonable risk assessment tool for an entire region, it cannot be applied to assess the risk of individual torrents. Additionally, it cannot determine the monetary value at risk. Remondo et al. (2008) developed a quantitative procedure for mapping landslide risk based on the hazard, the vulnerability and the values of exposed elements. In their analysis, landslide frequency for the next 50 years was estimated using historical landslide records, and vulnerability was estimated by comparing losses with the actual values of affected elements. Their analytical results were then presented in a risk map. Zêzere et al. (2007) analyzed landslide risk and evaluated direct and indirect costs resulting from a road disruption caused by slope movement. In their analysis, landslide hazard maps were developed based on a scenario for landslides in the next 27 years. The potential cost due to road disruption was estimated using a pragmatic-oriented approach. These two methods assessed risk in terms of monetary value, which can be compared with the cost of preventive measures. However, the resilient capacity of residents was not considered.

This work assesses risk by considering the probability of the occurrence of debris flows, the expected loss, and the resilient capacity, with the vulnerability and the values of elements at risk included in the expected loss calculation. During analysis, an affected area can be classified as a red or yellow hazard zone based on sediment deposition depth. Annual rainfall data are used to establish the probability of the occurrence of debris flows. Annual risks are expected losses divided by recurrence intervals and are related to the investi- gation period. Losses of property and lives are incorporated into a vulnerability analysis. The representative value and the damage factor for individual elements at risk are used to predict property losses. The vulnerability of residents in buildings can be included to quantify the lives lost. Community resilient capacity, measured by "disaster resilient capacity of residents" (abbr. "Resident Capacity") and "community resources for disaster resilience", (abbr. "Community Resources") is estimated based on the results of resident questionnaires and community checklists. Finally, maps of expected property loss and expected total loss are developed to show their spatial distribution. Risk reduction programs should be prioritized based on benefit and cost analysis results.

Debris flows occurred in 2000, 2002, 2004 and 2005 in the Songhe community, Taichung County, Taiwan. The debris flow in 2004 caused by Typhoon Mindull was particularly severe and buried 30 houses, killing four people (Soil and Water Conservation Bureau, 2005). Since 2001, several integrated mitigation structures have been implemented. Two disaster prevention education and training plans, including evacuation drills in 2000 and 2005, were held in the Songhe community. We chose this community for our case study to demonstrate the application of the proposed method.

\section{Methodology}

\subsection{Hazard analysis}

The relationship between the frequency and the intensity of a hazard event can be established from observed data. In reality, data characterizing most natural hazards are insufficient for such a derivation using an empirical approach. Therefore, new approaches are needed to overcome the difficulties associated with insufficient data. For instance, because heavy rainfall is the main cause of debris flows, rainfall frequency and intensity are represented by frequency/intensity classes, and debris flows are represented by movement classes. Forte et al. (2005) established nine indices for hazard degree based on three classes of rainfall intensity and three classes of rainfall frequency. Similarly, Cardinali et al. (2002) proposed that the degree of landslide hazard depends on landslide frequency and intensity. Therefore, they characterized landslides using four frequency classes and four intensity classes; the intensity classes were based on observed volume and velocity.

Several studies have reported that the deposition depth and maximum velocity of debris flows affect the hazard level. Rickenmann (2001) simulated debris flows for return periods of 10, 100 and 1000 years and classified the affected area into high, medium and low hazard zones based on deposition depth and maximum velocity; the delineation criterion was related to the legal situation in Switzerland. Fiebiger (1997) described how the Federal Forest Technical Service of Torrent and Avalanche Control, Austria, classifies hazard zones. 
Table 1. Delineation criteria of hazard zones for debris flows.

\begin{tabular}{lccc}
\hline & High hazard zone & Medium hazard zone & Low hazard zone \\
\hline Rickenmann (2001) & $h>1.5 \mathrm{~m}$ or $v>1.5 \mathrm{~m} / \mathrm{s}$ & $\begin{array}{c}h \leq 1.5 \mathrm{~m} \text { and } \\
0.5 \mathrm{~m} / \mathrm{s} \leq v \leq 1.5 \mathrm{~m} / \mathrm{s}\end{array}$ & $h<0.5 \mathrm{~m}$ and $v<0.5 \mathrm{~m} / \mathrm{s}$ \\
Fiebiger (1997) & $h \geq 0.7 \mathrm{~m}$ & - & $h<0.7 \mathrm{~m}$ \\
Tang et al. (2006) & $h>1.0 \mathrm{~m}$ and $v>3.0 \mathrm{~m} / \mathrm{s}$ & $0.5 \mathrm{~m} \leq h \leq 1.0 \mathrm{~m}$ and & $h<0.5 \mathrm{~m}$ and $v<1.0 \mathrm{~m} / \mathrm{s}$ \\
& & $1.0 \mathrm{~m} / \mathrm{s} \leq v \leq 3.0 \mathrm{~m} / \mathrm{s}$ & \\
Huggel et al. (2006) & $h \geq 2.0 \mathrm{~m}$ & - & $h<2.0 \mathrm{~m}$ \\
Present study & $h \geq 0.5 \mathrm{~m}$ & - & $h<0.5 \mathrm{~m}$ \\
& (red hazard zone) & & (yellow hazard zone) \\
\hline
\end{tabular}

$h$ is deposition depth; $v$ is velocity.

The events with return periods of 10 years and 150 years were first simulated, and high and low hazard zones were then delineated based on simulated deposition depth; the delineation criterion was related to the Forest law in Austria. Tang et al. (2006) investigated debris flows in a basin in China and delineated hazard zones based on observed deposition depths and velocities. Huggel et al. (2006) delineated high and low hazard zones based on deposition depth (Table 1).

In this study, we used only deposition depth as an input parameter for hazard levels. The hazard zones with deposition depths greater than $0.5 \mathrm{~m}$ were designated as red zones, whereas those with deposition depths less than $0.5 \mathrm{~m}$ were yellow zones. There are several reasons for choosing a deposition depth of $0.5 \mathrm{~m}$ as a separation point. The first is that the major type of debris flow in Taiwan is stony debris flow, and residents cannot move about when coarse particles are deposited above the knee. Therefore, the separation point was chosen based on the average knee height of residents, i.e. $0.5 \mathrm{~m}$. The second reason is that the observed property losses were much higher when deposition depths exceeded $0.5 \mathrm{~m}$ because most pieces of furniture are located within $0.5 \mathrm{~m}$ a.g.l. Another reason is that crop losses increased remarkably when deposition depths exceeded $0.5 \mathrm{~m}$ in farmlands. Additionally, one of the reasons for only considering deposition depth (and not flow velocity) as an input parameter is that the observed losses of houses, which are generally built with reinforced-concrete in Taiwan, were mainly caused by debris depositions but not house breaks. Another reason is that flow velocities can be recorded in simulation processes but cannot be observed in the field.

The FLO-2D model (O'Brien et al., 1993) was used to simulate the deposition of debris flow torrents. Although the scale of debris flows depends on precipitation and available transport sediment, only precipitation was used as a proxy in the FLO-2D model because of the difficult question of whether sediment will be (re) mobilized. The steps for beginning a simulation with FLO-2D, which include obtaining topographic data and developing flood hydrology, were proposed by Bertolo and Wieczorek (2005). Since an inflow flood hydrograph was required, a triangular hydrograph was used to simplify the process, and the peak discharges were evaluated using the rational formula based on small areas of watersheds (Pilgrim and Cordery, 1993). Related parameters were calibrated with a trial-and-error procedure comparing field surveys. It is worth nothing that the recurrence interval of a debris flow is the reciprocal of the occurrence probability. Therefore, annual risks can be calculated as expected losses divided by the recurrence interval for events with 5-, 10 - and 50-year return periods.

\subsection{Vulnerability analysis}

Vulnerability is the threat or harm to residents and property posed by a disaster. In this study, vulnerability was defined as the expected degree of loss with a value in the range of 0 to 1 for an element at risk as a consequence of a certain event. Several methods have been proposed to simplify this complex analysis. For example, Cardinali et al. (2002) estimated vulnerability by inferring the relationship between the intensity and the type of expected landslides as well as the probable damage that landslides would cause to 11 risk elements. The expected damage to the elements was classified as superficial, functional or structural. However, this approach, which is a type of qualitative analysis, did not suggest any vulnerability values in the risk assessments. Forte et al. (2005) used nine classes of vulnerability to classify elements at risk. Each class had one fictitious multiple of three indices so that vulnerability was numerically defined by the values. However, this approach, which is a type of semiquantitative analysis, can express the comparative susceptibility of elements at risk but cannot express absolute susceptibility. Fuchs et al. (2007a) established a relationship between debris flow intensity and the vulnerability of buildings constructed of bricks and concrete. The mean vulnerabilities for intensity classes of $0.5,1.0,1.5,2.0$, and $2.5 \mathrm{~m}$ were taken to be $0.02,0.03,0.21,0.45$, and 0.52 , respectively. This approach suggested a second order polynomial function relationship between debris flow intensity and vulnerability and supported an enhanced standardization of the vulnerability function. 
Table 2. Damage factors (DF) and assessment methods of elements at risk.

\begin{tabular}{|c|c|c|c|}
\hline \multirow{2}{*}{$\begin{array}{l}\text { Elements } \\
\text { at risk }\end{array}$} & \multicolumn{2}{|c|}{ DF } & \multirow{2}{*}{$\begin{array}{l}\text { Assessment method of } \\
\text { value of element }\left(V_{\mathrm{e}}\right)\end{array}$} \\
\hline & $\begin{array}{c}\text { Red } \\
\text { hazard } \\
\text { zone }\end{array}$ & $\begin{array}{c}\text { Yellow } \\
\text { hazard } \\
\text { zone }\end{array}$ & \\
\hline House & 0.3 & 0.1 & Assessed house value \\
\hline Farmland & 1.0 & 1.0 & $\begin{array}{l}\text { Assessed product value } \\
\text { per unit area }\end{array}$ \\
\hline Forestland & 0.5 & 0.1 & $\begin{array}{l}\text { Assessed forestland value } \\
\text { per unit area }\end{array}$ \\
\hline Road & 1.0 & 0.5 & $\begin{array}{l}\text { Published costs of newly } \\
\text { constructed road }\end{array}$ \\
\hline Bridge & 1.0 & 0.5 & $\$ 746$ per $\mathrm{m}^{2}$ \\
\hline River & - & - & $\$ 0$ per $\mathrm{m}^{2}$ of surface area \\
\hline
\end{tabular}

The vulnerability value depends on deposition depth and the susceptibility of an exposed element. To assess loss, damage factors from Team KNU (2005) can be adopted to represent the average ratio of actual losses to the values of elements in the red and yellow hazard zones in this study. The product of damage factor and the value of an element is the average loss over several disasters of the same scale, and this knowledge allows us to carry out a quantitative risk analysis. Table 2 shows the proposed damage factors for elements at risk in the red and yellow hazard zones.

Only losses of property and human life were considered in our risk analysis. Indirect losses and intangible losses caused by disasters were ignored. To estimate property loss, a GIS land-use layer was established by digitizing aerial photographs of an affected area. Land-use was classified based on the types of risk elements, such as houses, farmland, forestland, roads, bridges and rivers. Additionally, GIS was used to determine the representative values of individual elements for calculating property loss.

In this study, house values were defined as the values assessed by the taxation bureau; farmland values were estimated based on area, annual production per unit area, and market values of agricultural products; forestland values were estimated based on area and the value per unit area assessed by Forestry Bureau; road values were estimated based on published cost data for new roads; bridge values were taken at $\$ 746 / \mathrm{m}^{2}$ as proposed by Liu and $\mathrm{Li}(2006)$. Table 2 summarizes these assessment methods. Additionally, we adopted the method used by Bell et al. (2004) to assess the vulnerability of residents in buildings $\left(V_{\mathrm{r}}\right)$ in Iceland during debris flows; these values were $0.02,0.06$ and 0.25 for debris flows with return periods of 5,10 , and 50 years, respectively. The life value $\left(V_{1}\right)$ is set at about $\$ 0.63$ million, as proposed by Liu and $\mathrm{Li}$ (2006) for risk analyses of debris flows in Taiwan.

\subsection{Resilient capacity analysis}

Resilient capacity refers to the capacity of individuals or a community to endure and resist disasters. Chen et al. (2005) considered community resilient capacity to be the combined effect of legal right to ask for the disaster prevention budget, disaster prevention and response organization, communication capability, warning capability, the ability to pay for mitigation and disaster prevention education. In other words, it represents how a community is for a disaster. Wang (2005) interviewed community leaders to assess community preparedness for disasters, which included responding, monitoring and communication systems. Wu (2006) improved upon this model using questionnaires given to residents for assessing resilient capacity based on resident responding, monitoring and communication capabilities.

This work places the resilient capacity of a community into two categories including "Resident Capacity" and "Community Resources" using the Analytic Hierarchy Process (AHP). The assessment framework for community resilient capacity consists of five hierarchies proposed by Chen et al. (2009). The first hierarchy is divided into the two stated categories. For other hierarchies, the categories can be subdivided into several subcategories. The proposed assessment method is as follows:

1. The category of "Resident Capacity" is divided into three subcategories of capabilities that residents possess to resist disasters, including responding, monitoring and communication. The assessment was conducted using resident questionnaires ( $\mathrm{Wu}, 2006)$. The score assigned to each question was in the range of 0 and 1; a high score indicates a high capability of resisting disasters.

2. The category of "Community Resources" is divided into three subcategories of community capabilities, including responding, monitoring and communication systems. This assessment utilized checklists for interviewing community leaders ( $\mathrm{Wu}, 2006)$. The score assigned to each question was in the range of 0 and 1; capability increased as the score increased.

3. The scores for the two categories of "Resident Capacity" and "Community Resources" were weighted to reflect the relative importance of a question within a subcategory, of a subcategory within a category, and of a category within the framework. The weights for different questions in a subcategory (with a sum of 1), for subcategories in a category (with a sum of 1), and for categories in the framework (with a sum of 1) were determined based on questionnaire responses from professionals (Chen et al., 2009). The total weight of a question, representing its relative importance among other questions, is the product of the above weights applicable to that question. The adjusted score for a given question was obtained by multiplying the score with 
the corresponding total weight. The sum of the adjusted scores for all questions of a category is the assessment score for that category, i.e., "Resident Capacity" or "Community Resources."

4. Finally, the sum of the adjusted scores for all questions is the score for the entire community's resilient capacity. The value is in a range of 0 to 1 .

\subsection{Risk analysis}

The risk value $(R)$ was calculated based on the analytical results for hazard, vulnerability, and resilient capacity. Vulnerability is divided into property loss and life loss, and risk is similarly divided. In addition, resilient capacity only accounts for the reduction of life loss due to the resilient capacity of residents; it cannot be combined with the property loss calculation because of the immobile risk elements. Therefore, the risks of property and life losses should be analyzed individually. Expected property loss (EL $\left.\mathrm{E}_{\text {property }}\right)$ for an element can be calculated as the product of damage factor (DF) and value of the element $\left(V_{\mathrm{e}}\right)$, as expressed by Eq. (1). Expected life losses $\left(\mathrm{EL}_{\text {life }}\right.$ ) can be calculated based on damage factor (DF), value of life $\left(V_{1}\right)$, vulnerability of residents in buildings $\left(V_{\mathrm{r}}\right)$, and resilient capacity $(C)$, as expressed by Eq. (2).

$$
\begin{aligned}
& \mathrm{EL}_{\text {property }}=\sum \mathrm{DF} \cdot V_{\mathrm{e}} \\
& \mathrm{EL}_{\text {life }}=\sum \mathrm{DF} \cdot V_{1} \cdot V_{\mathrm{r}} \cdot(1-C)
\end{aligned}
$$

Expected loss maps were developed to show the spatial distribution of expected loss in an affected area to prioritize risk reduction tasks. These maps can also be used to identify the changes of expected loss due to the installation of mitigation structures and the implementation of evacuation measures. Further, expected loss maps demonstrate that mitigation structures may not ensure absolute safety.

Risk in this study is defined as the product of the occurrence probability of debris flows $\left(P_{\mathrm{d}}\right)$ and expected losses, such that annual risk for a debris flow event ( $\left.R_{\text {event }}\right)$ is calculated using Eq. (3). In Eq. (3), $P_{\mathrm{d}}$ is the occurrence probability of debris flows. Alternatively, annual risk is calculated as the expected losses divided by the recurrence interval.

$$
R_{\text {event }}=P_{\mathrm{d}} \cdot \mathrm{EL}_{\text {property }}+P_{\mathrm{d}} \cdot \mathrm{EL}_{\text {life }}
$$

The event losses for different recurrence probabilities can be used to establish the loss frequency function (Peter, 2003). Total annual risk $\left(R_{\text {total }}\right)$ is calculated by integrating the frequency function; reduced total annual risk is the benefit of the reduction program.

\subsection{Benefit-cost analysis of the risk reduction program}

Cost effectiveness analysis (CEA) and benefit-cost analysis (BCA) can be applied to evaluate a risk reduction program. Notably, CEA provides information about whether a given program is more cost-effective than others, but not about whether it contributes to an increase in resident welfare (Groot et al., 2004). Conversely, BCA can assess the shifts in resident welfare. Fuchs et al. (2007b) applied CEA and BCA to evaluate alternative programs for avalanche risk reduction. Their analytical results suggested a close approximation to the economic and cost efficiencies of the risk reduction program applied, including a reduction of fatality risk. A program with a benefit-cost ratio exceeding 1.0 is considered to be economically efficient.

Reduced total annual risk can be achieved by mitigation structures, delimitation of the Designated Soil and Water Conservation Area and evacuation measures; this reduced risk is considered to be the protection benefit. This benefit can be calculated as total annual risk prior to the implementation of reduction programs minus the risk after implementation. To be conservative, we assumed that the residents took no evacuation actions during the events prior to the implementation of reduction programs. In other words, resilient capacity $(C)$ was zero under this assumption.

The total cost of the risk reduction program cannot be used directly for the benefit-cost analysis. Instead, the total cost of the risk reduction program should be converted into an annual $\operatorname{cost}\left(C_{\text {annual }}\right)$ using the following equation:

$C_{\text {annual }}=C_{\text {primary }} \cdot \frac{i(1+i)^{n}}{(1+i)^{n}-1}$

where $C_{\text {annual }}=$ annual cost,$C_{\text {primary }}=$ total primary cost, $i=$ annual interest rate (\%), $n=$ term (year). The benefit-cost ratio for a program can be calculated by dividing reduced total annual risk by the annual cost.

\section{Case study}

\subsection{Environmental setting of the Songhe community}

The Songhe community is located in Taichung County, Taiwan. At an elevation of about $700 \mathrm{~m}$, it has an annual average temperature of $22^{\circ} \mathrm{C}$ and mean annual rainfall of $2807 \mathrm{~mm}$. The Nos. 1 and 2 Torrents pass through the community and can cause dangerous debris flows. The upstream watershed has an elongated shape with the long axis running in the eastwest direction. The watershed area and length are about 375 ha and $4300 \mathrm{~m}$ for the No. 1 Torrent, and 55 ha and $1800 \mathrm{~m}$ for the No. 2 Torrent, respectively. The watershed has a steep topography with elevations ranging from 640 to $2870 \mathrm{~m}$. Figure 1 shows the torrents and topography of the Songhe community. The geology of the area is characterized by well-developed joints and strata of argillites and sandstones with expose $d$ surfaces often revealing signs of weathering. The area has become increasingly susceptible to debris flows since the Chichi Earthquake in 1999, which caused wide-spread landslides and generated considerable amounts of loose material for debris flows. 


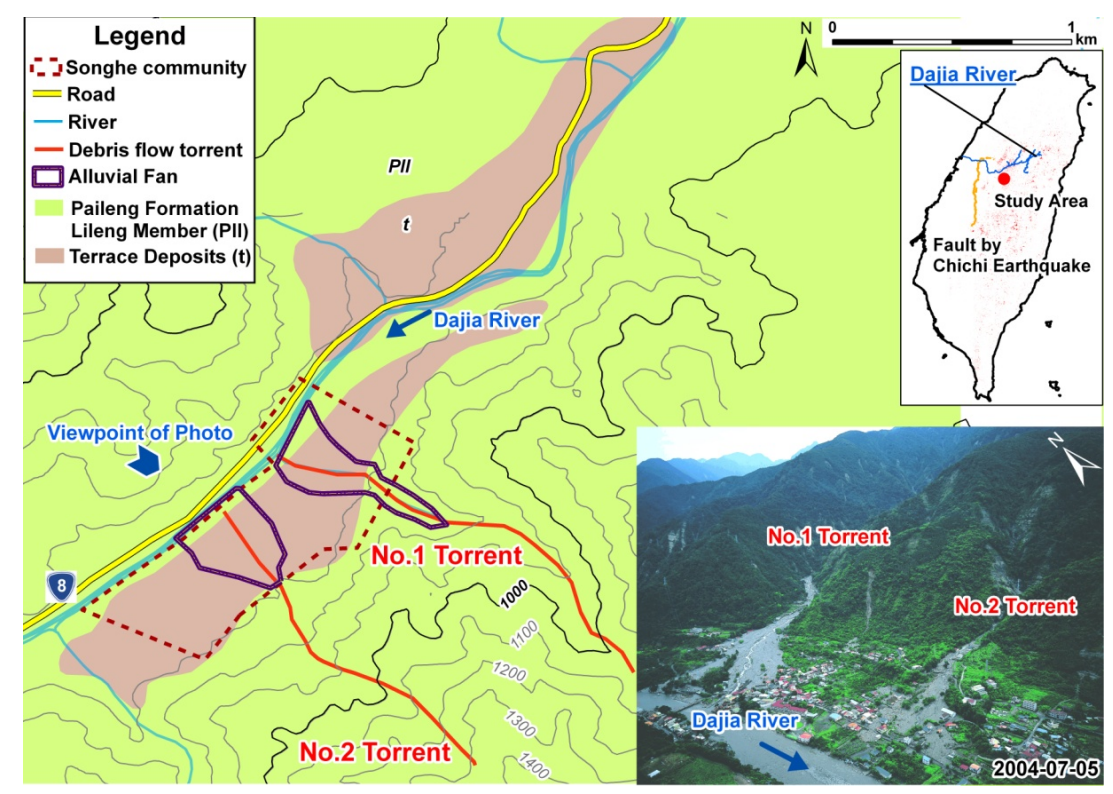

Fig. 1. Locations of two debris flow torrents in the Songhe community. Destruction caused by Typhoon Mindulle in 2004 is shown in the photograph.

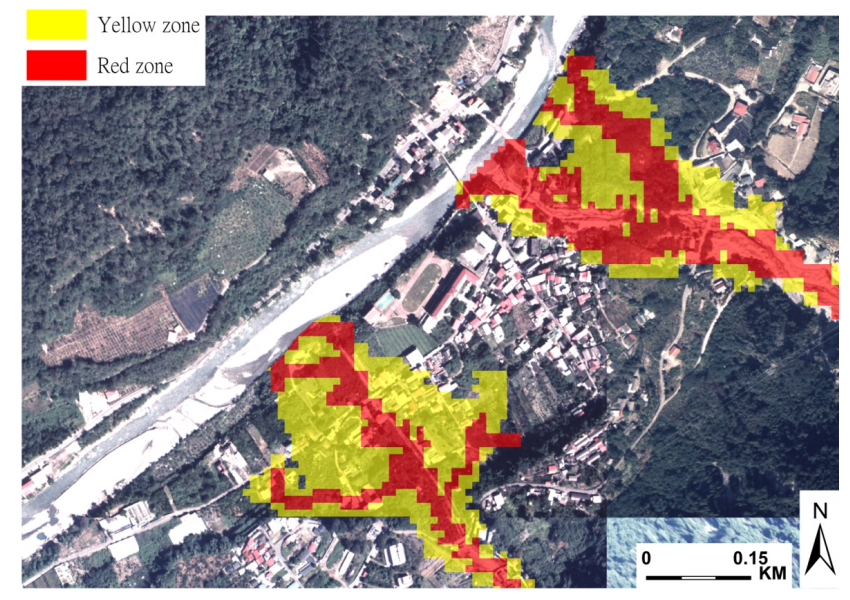

Fig. 2. Distribution of hazard zones for the Nos. 1 and 2 Torrents.

\subsection{Risk analysis of debris flow disasters}

\subsubsection{Hazard analysis}

Regarding the FLO2D model parameters used in the analyses, for the input triangular hydrograph the times of concentration are about $31 \mathrm{~min}$ and $17 \mathrm{~min}$ for the Nos. 1 and 2 Torrents, respectively; rainfall intensities with different return periods were calculated based on the annual precipitation data. Peak discharges calculated by the rational formula for the 5-, 10- and 50-year return periods were 100.1, 112.1 and $139.9 \mathrm{~m}^{3} / \mathrm{s}$ for the No. 1 Torrent, respectively, and 14.6, 16.4 , and $20.4 \mathrm{~m}^{3} / \mathrm{s}$ for the No. 2 Torrent, respectively. For the viscosity $\mu$ (where $\mu=\alpha_{1} \cdot e^{\beta_{1} \cdot C_{\mathrm{v}}}$ ), we used a coefficient of 0.005 and an exponent of 11.24, and for the yield stress $\tau_{y}$ (where $\tau_{y}=\alpha_{2} \cdot e^{\beta_{2} \cdot C_{\mathrm{v}}}$ ), we used a coefficient of 0.811 and an exponent of 13.72. Related parameters, starting from the values found in the literature (FLO-2D Users Manual, 2003), were calibrated with a trial-and-error procedure comparing field survey with the event in 2004. The maximum sediment concentration by volume $\left(C_{\mathrm{v}}\right)$ during the simulation reached $40 \%$. The Manning's coefficient n-values, based on field observations, ranged from 0.04 to 0.1 .

The FLO-2D model was then used to simulate depositions for the Nos. 1 and 2 Torrents based on a $10 \times 10 \mathrm{~m}$ DTM dataset. The results were used to delineate the red and yellow hazard zones and to determine the corresponding hazard degrees for the Nos. 1 and 2 Torrents (Fig. 2). Most of the 30 houses buried by debris flows during Typhoon Mindulle in 2004 were within the delineated red zones.

\subsubsection{Vulnerability analysis}

ArcView (ESRI, 2002) was used to digitize the land-use layer based on 1/5000 orthophotos for estimating the values of elements at risk. The distribution of elements in the hazard zones of the Nos. 1 and 2 Torrents is shown in Fig. 3. Buildings in this community were mostly twostory reinforced-concrete houses with typical unit values of $\$ 72 / \mathrm{m}^{2}$ and $\$ 75 / \mathrm{m}^{2}$ for the first floor and the second floor, respectively (Taichung County Revenue Agency, 2007). House values were estimated based on building footprints and a combined unit value of $\$ 147 / \mathrm{m}^{2}$. Farmland values were estimated based on area and a unit price of $\$ 1.75 / \mathrm{m}^{2}$, which was in turn estimated based on annual production per unit area and the market price of agricultural products, including 
Table 3. Resilient capacity scores for the Songhe community.

\begin{tabular}{lll}
\hline Assessment Category/subcategory & Score & Total weight \\
\hline Resilient capacity of community & 0.611 & 1.000 \\
\hline Disaster resilient capacity of residents & 0.632 & 0.498 \\
- Responding capability & 0.494 & 0.208 \\
Understanding the community's disaster prevention and response organization & 0.556 & 0.043 \\
Preparing the disaster prevention resources of one's own house & 0.560 & 0.050 \\
Understanding the emergency evacuation route and shelter & 0.482 & 0.067 \\
Acquiring disaster prevention experience & 0.387 & 0.048 \\
- Monitoring capability & 0.634 & 0.135 \\
Observing the one's own rainfall gauge & 0.656 & 0.083 \\
Experience principle & 0.596 & 0.052 \\
- Communication capability & 0.817 & 0.155 \\
Communicating with the supervisors, relatives or neighbors & 0.817 & 0.155 \\
\hline Community resources for disaster resilience & 0.589 & 0.502 \\
- Responding system & 0.473 & 0.204 \\
Disaster prevention and response organization & 0.285 & 0.057 \\
Disaster prevention and response resources & 0.352 & 0.070 \\
The emergency evacuation planning & 0.722 & 0.077 \\
- Monitoring system & 0.853 & 0.136 \\
Real-time monitoring system & 0.860 & 0.062 \\
Observing the community's rainfall gauge & 0.849 & 0.074 \\
- Communication system & 0.513 & 0.162 \\
Communication equipment and feedback system & 0.513 & 0.162
\end{tabular}

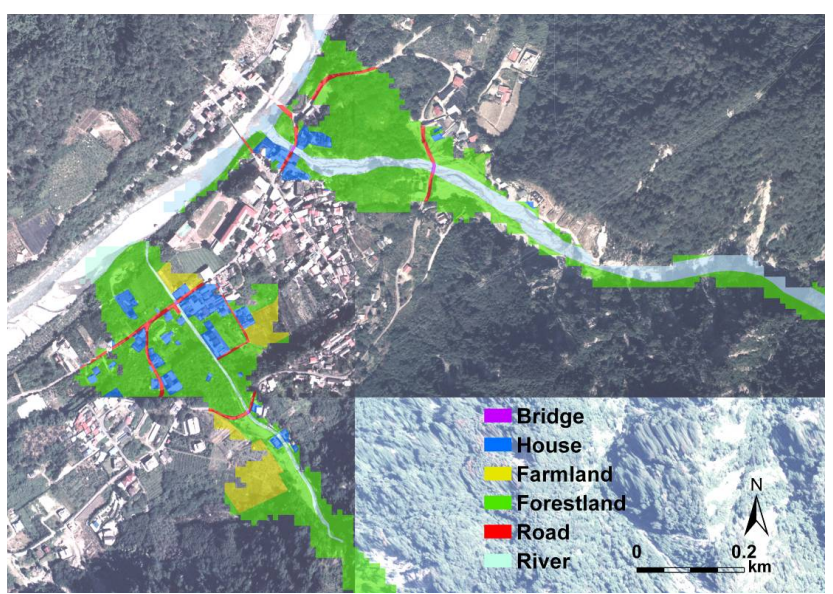

Fig. 3. Location map for elements at risk in the hazard zones of the Nos. 1 and 2 Torrents.

peaches, plums and pears (Agriculture and Food Agency, 2006). Forestland values were estimated based on area and a unit price of $\$ 0.44 / \mathrm{m}^{2}$ (Forestry Bureau, 2006). Values of roads were estimated based on the paved surface areas and the published unit construction cost of $\$ 75 / \mathrm{m}^{2}$ (Construction and Planning Agency, 2007).
The actual number of occupants per house in the area was unavailable. An average of 2.2 occupants per household was estimated based on the number of the houses (394) and total population (848) in the Songhe community (Heping Township Household Registration Office, Taichung County, 2007). The average number of residents per square meter $\left(P_{\mathrm{a}}\right)$ of 0.0275 was calculated according to a typical house size of $80 \mathrm{~m}^{2}$ based on the entire area of the Songhe community. This number was used with a life value of about $\$ 0.63$ million and the vulnerability of residents in buildings $\left(V_{\mathrm{r}}\right)$ to calculate expected life loss.

\subsubsection{Resilient capacity analysis}

Community resilient capacity was assessed using questionnaires and checklist results based on the proposed method. These results are shown in Table 3. The "Resident Capacity" and "Community Resources", have similar weights, indicating that both are equally important. The two most important subcategories are "responding capability" and "responding system". However, since both scores are low, the Songhe community must improve in this regard.

The evacuation measure is based on an early warning system as shown in Table 3. The levels of the debris flow warning system in Taiwan were classified with respect to a yellow alarm and a red alarm. When the predicted precipitation is 
Table 4. Expected losses and annual risk of debris flows for Nos. 1 and 2 Torrents.

\begin{tabular}{llrrrr}
\hline \multirow{2}{*}{ Return period } & & \multicolumn{2}{c}{ No. 1 Torrent } & \multicolumn{2}{c}{ No. 2 Torrent } \\
\cline { 3 - 6 } & Assessment item & $\begin{array}{r}\text { Expected losses } \\
(\$)\end{array}$ & $\begin{array}{r}\text { Annual risk } R_{\text {event }} \\
(\$ / y r)\end{array}$ & $\begin{array}{r}\text { Expected losses } \\
(\$)\end{array}$ & $\begin{array}{r}\text { Annual risk } R_{\text {event }} \\
(\$ / y r)\end{array}$ \\
\hline \multirow{5}{*}{5 years } & Property risk & 399678 & 79936 & 427692 & 85538 \\
& Life risk & 291116 & 58223 & 567383 & 113477 \\
& Total risk & 690795 & 138159 & 995076 & 199015 \\
10 years & Property risk & 413515 & 41352 & 463992 & 46399 \\
& Life risk & 953592 & 95359 & 1878989 & 187899 \\
& Total risk & 1367107 & 136711 & 2342981 & 234298 \\
50 years & Property risk & 452236 & 9045 & 525370 & 10507 \\
& Life risk & 4372482 & 87450 & 8728776 & 174576 \\
& Total risk & 4824719 & 96494 & 9254146 & 185083 \\
\hline
\end{tabular}

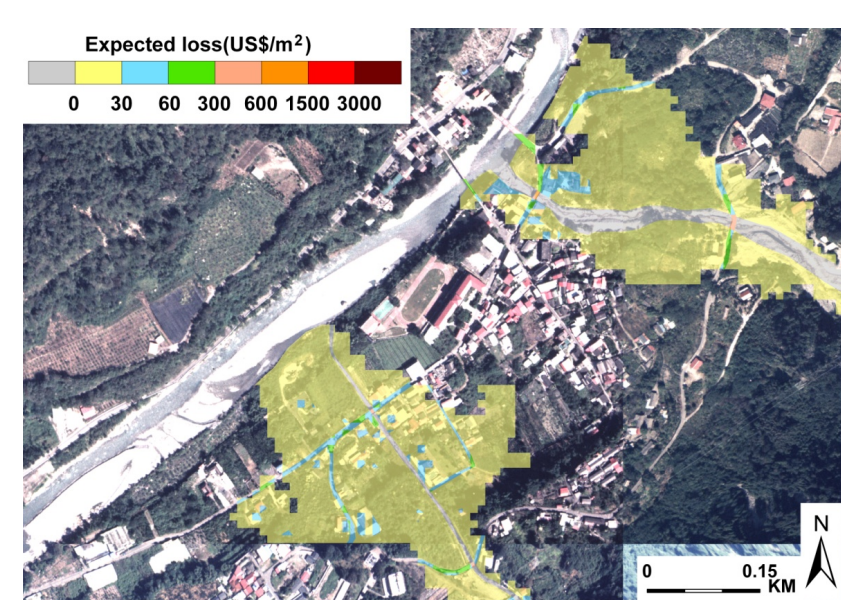

Fig. 4. Map showing the spatial distribution of expected property loss caused by debris flows of the Nos. 1 and 2 Torrents for an event with 50-year return period.

greater than the warning threshold (e.g., $300 \mathrm{~mm}$ in the study area), a yellow alarm for a debris flow is announced to the affected community, and the local government will advise residents to evacuate. When the actual accumulated precipitation reaches the warning threshold, a red alarm will be announced, and the local government will enforce residents to evacuate. Local policemen and fire fighters also assist residents in evacuation, and those who refuse will be forced to evacuate to safe shelters.

Professional debris-flow volunteers living in the community were also trained to assist the government in providing debris-flow warnings to residents and strengthening the self-rescue ability of the community. The volunteers used simple rainfall gauges and communication equipment to observe the local real-time precipitation and to communicate the situation with the supervisors, relatives or neighbors.

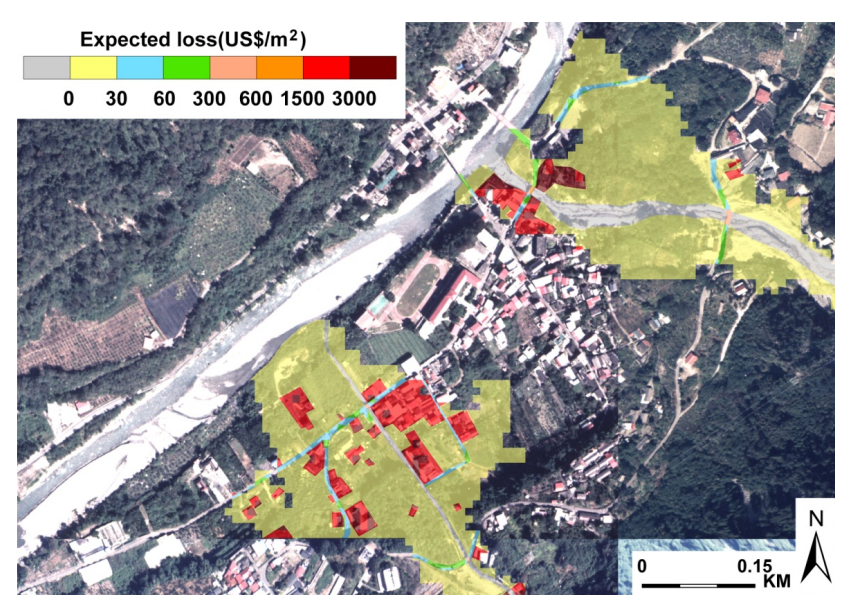

Fig. 5. Map showing the spatial distribution of expected total loss caused by debris flows of the Nos. 1 and 2 Torrents for an event with 50-year return period.

\subsubsection{Risk analysis}

The expected property and life losses were calculated using Eqs. (1) and (2), respectively. The expected property loss and expected life loss before the risk reduction program was implemented were summed to obtain expected total losses (Table 4) for events with the 5-, 10- and 50-year return periods. Our analytical results show that as the size of a debris flow increases, the size of the affected area increases and, consequently, expected losses increase. Spatial distributions of expected property loss and expected total loss for the Nos. 1 and 2 Torrents for an event with the 50-year return period are shown in Figs. 4 and 5, respectively. Using expected total losses for events with different return periods in Table 4 , loss frequency curves for both torrents were then drawn, and total annual risks ( $\left.R_{\text {total }}\right)$ were calculated to be $\$ 0.72$ million and $\$ 1.22$ million for the Nos. 1 and 2 Torrents, respectively. 
Table 5. Risk reduction program for debris flows in Songhe community.

\begin{tabular}{|c|c|c|c|c|}
\hline & \multicolumn{3}{|c|}{ Risk reduction program } & Primary cost $(\$)$ \\
\hline \multirow{10}{*}{$\begin{array}{l}\overrightarrow{0} \\
\stackrel{0}{0} \\
\stackrel{0}{0} \\
\dot{0} \\
\dot{z}\end{array}$} & & Height of the dam (m) & Torrent's average width $(\mathrm{m})$ & \\
\hline & No. 1 check dam & 5 & 40 & 80000 \\
\hline & No. 2 check dam & 5 & 24 & 50149 \\
\hline & Restoration of the check dam & 5 & 24 & 50149 \\
\hline & No. 3 check dam & 5 & 24 & 50149 \\
\hline & No. 4 check dam & 5 & 24 & 50149 \\
\hline & Restoration of the check dam & 5 & 24 & 50149 \\
\hline & No. 5 check dam & 6 & 30 & 95821 \\
\hline & Settling basin & $\begin{array}{l}\text { Area: } 2.6 \text { ha; } \\
\text { Average depth: } 5 \mathrm{~m} \text {; } \\
\text { Width: } 24 \mathrm{~m}-175 \mathrm{~m}\end{array}$ & & 1488149 \\
\hline & Total expenditures of mitigation str & ctures for No. 1 Torrent & & 1903970 \\
\hline \multirow{3}{*}{$\begin{array}{l}\overrightarrow{0} \\
0 \\
\stackrel{0}{0} \\
\stackrel{0}{N} \\
\dot{0}\end{array}$} & Revetment & Total length: $724.5 \mathrm{~m}$ & & 480388 \\
\hline & Retaining wall & $\begin{array}{l}\text { Average height: } 5 \mathrm{~m} \text {; } \\
\text { Total length: } 252 \mathrm{~m}\end{array}$ & & 39493 \\
\hline & Total expenditures of mitigation str & ctures for No. 2 Torrent & & 519881 \\
\hline \multirow{5}{*}{ 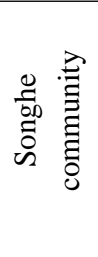 } & First disaster prevention drill & 11 August 2000 & & 29851 \\
\hline & Second disaster prevention drill & 22 August 2005 & & 5373 \\
\hline & Monitoring system & Real-time monitoring $\mathrm{s}$ & stem and rainfall gauge & 89552 \\
\hline & Professional debris-flow volunteer & 5 Volunteers in Songhe & ommunity & 3730 \\
\hline & \multicolumn{3}{|c|}{ Total expenditures of evacuation measures } & 128507 \\
\hline
\end{tabular}

\subsection{Risk reductions after reduction program implementation}

Risk reduction programs, including mitigation structures, delimitation of the Designated Soil and Water Conservation Area and evacuation measures, have been implemented in the Songhe community. Mitigation structures included bank revetments, check dams, and settling basin, whereas evacuation measures included drills for disaster resistance, a monitoring system and participation of professional debris-flow volunteers (SWCB, 2005) (Table 5). Among the mitigation structures, the No. 5 check dam is located upstream, whereas the settling basin is located downstream. To assess the effectiveness of the reduction program, the FLO-2D model was applied to simulate hazard zones for the Nos. 1 and 2 Torrents after mitigation structures were installed.

Figure 6 shows the spatial distributions of expected total losses, indicating that size of areas in the red and yellow hazard zones were reduced and the paths of debris flow torrents were altered comparing with the pre-installation conditions. The areas of reduced hazard zones were about 6.75 ha and 4.03 ha for the Nos. 1 and 2 Torrents, respectively, and the

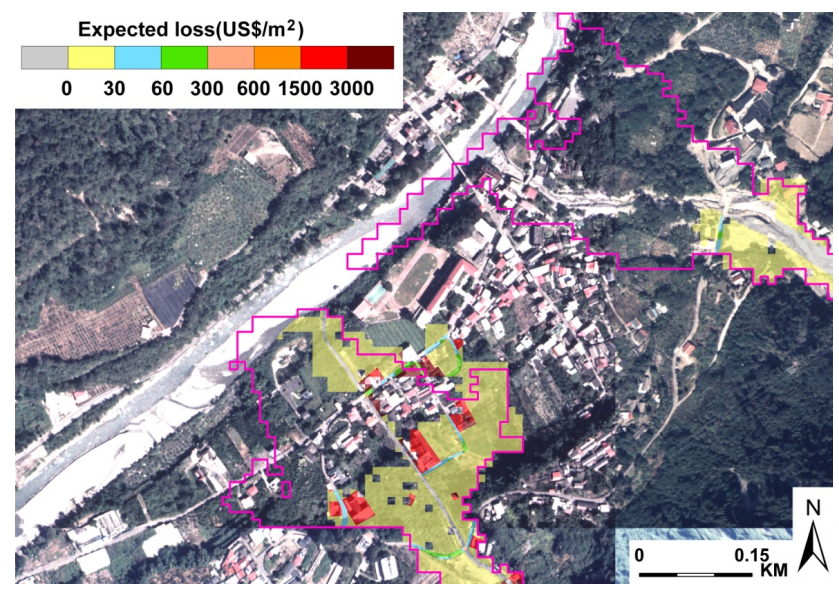

Fig. 6. Map showing the expected total loss caused by debris flows of the Nos. 1 and 2 Torrents for an event with 50-year return period after mitigation structures were installed. The pink line is the boundary of the simulated debris flow deposits in Fig. 2. 
Table 6. Total annual risks, benefits, annual costs, and the benefit-cost ratio when mitigation structures are combined with evacuation measures for the Nos. 1 and 2 Torrents.

\begin{tabular}{|c|c|c|c|c|}
\hline & \multicolumn{4}{|c|}{ Total annual risks $\left(R_{\text {total }}\right)$ with or without mitigation structures and evacuation measures $(\$)$} \\
\hline & $\begin{array}{r}\text { No mitigation structures and } \\
\text { no evacuation measures }\end{array}$ & $\begin{array}{r}\text { Only mitigation } \\
\text { structures }\end{array}$ & $\begin{array}{r}\text { Only evacuation } \\
\text { measures }\end{array}$ & $\begin{array}{r}\text { Mitigation structures and } \\
\text { evacuation measures }\end{array}$ \\
\hline No. 1 Torrent & 723380 & 16786 & 430605 & 11111 \\
\hline \multirow[t]{3}{*}{ No. 2 Torrent } & 1213901 & 646036 & 634577 & 351140 \\
\hline & \multicolumn{3}{|c|}{ Benefit of mitigation structures and evacuation measures (\$) } & \\
\hline & $\begin{array}{r}\text { Benefit of mitigation } \\
\text { structures }\end{array}$ & $\begin{array}{r}\text { Benefit of evacuation } \\
\text { measures }\end{array}$ & $\begin{array}{r}\text { Benefit of combination of } \\
\text { mitigation structures and } \\
\text { evacuation measures }\end{array}$ & \\
\hline No. 1 Torrent & 706595 & 292776 & 712270 & \\
\hline No. 2 Torrent & 567865 & 579325 & 862761 & \\
\hline \multirow[t]{3}{*}{ Total } & 1274460 & 872100 & 1575031 & \\
\hline & \multicolumn{3}{|c|}{ Annual cost of mitigation structures and evacuation measures (\$) } & \\
\hline & $\begin{array}{l}\text { Annual cost of } \\
\text { mitigation structures }\end{array}$ & $\begin{array}{r}\text { Annual cost of } \\
\text { evacuation measures }\end{array}$ & $\begin{array}{r}\text { Annual cost of combination } \\
\text { of mitigation structures } \\
\text { and evacuation measures }\end{array}$ & \\
\hline No. 1 Torrent & 258689 & - & - & \\
\hline No. 2 Torrent & 70635 & - & - & \\
\hline \multirow[t]{3}{*}{ Total } & 329324 & 30507 & 359831 & \\
\hline & \multicolumn{3}{|c|}{ Benefit-cost ratio $(\mathrm{B} / \mathrm{C})$ of mitigation structures and evacuation measures } & \\
\hline & $\begin{array}{r}\mathrm{B} / \mathrm{C} \text { of mitigation } \\
\text { structures }\end{array}$ & $\begin{array}{r}\mathrm{B} / \mathrm{C} \text { of evacuation } \\
\text { measures }\end{array}$ & $\begin{array}{r}\mathrm{B} / \mathrm{C} \text { of combination of } \\
\text { mitigation structures and } \\
\text { evacuation measures }\end{array}$ & \\
\hline No. 1 Torrent & 2.73 & - & - & \\
\hline No. 2 Torrent & 8.04 & - & - & \\
\hline Total & 3.87 & 28.59 & 4.38 & \\
\hline
\end{tabular}

corresponding ratios of reduction were $86.87 \%$ and $55.43 \%$, respectively. Therefore, the mitigation structures reduced not only expected property loss but also expected life loss. Table 6 shows that after the installation of mitigation structures, total annual risks $\left(R_{\text {total }}\right)$ decreased to $\$ 0.02$ million from $\$ 0.72$ million for the No. 1 Torrent and to $\$ 0.66$ million from $\$ 1.22$ million for the No. 2 Torrent. Figure 7 shows the spatial distributions of expected total loss after the implementation of evacuation measures and indicates that an increase in the resilient capacity of residents decreased the expected life loss and total loss. Additionally, total annual risks $\left(R_{\text {total }}\right)$ decreased to $\$ 0.42$ million from $\$ 0.72$ million for the No. 1 Torrent and to $\$ 0.63$ million from $\$ 1.22$ million for the No. 2 Torrent (Table 6).

Figure 8 shows the spatial distributions of expected total loss after installation of mitigation structures and the implementation of evacuation measures, suggesting that the size of hazard zones and expected life loss decreased. Notably, Table 6 shows that total annual risks $\left(R_{\text {total }}\right)$ decreased to $\$ 0.01$ million from $\$ 0.72$ million for the No. 1 Torrent and

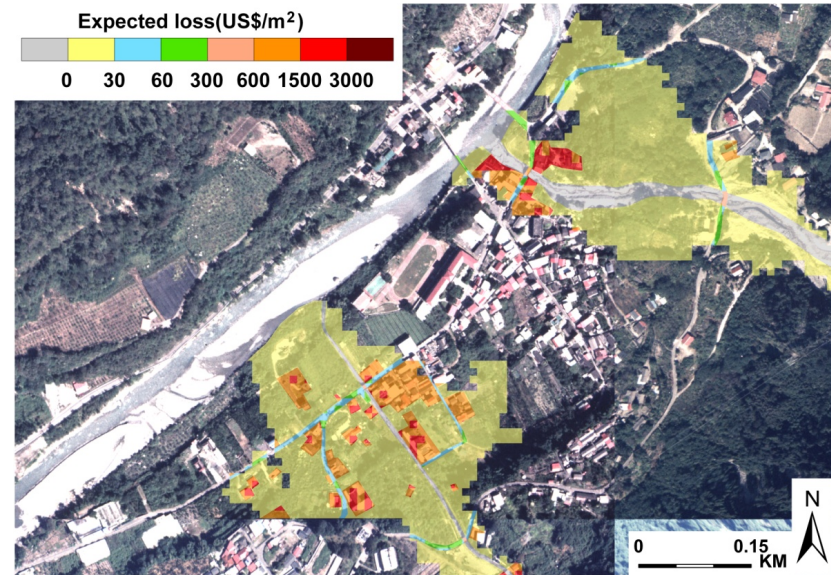

Fig. 7. Map showing the expected total loss caused by debris flows of the Nos. 1 and 2 Torrents for an event with 50-year return period after evacuation measures were implemented. 


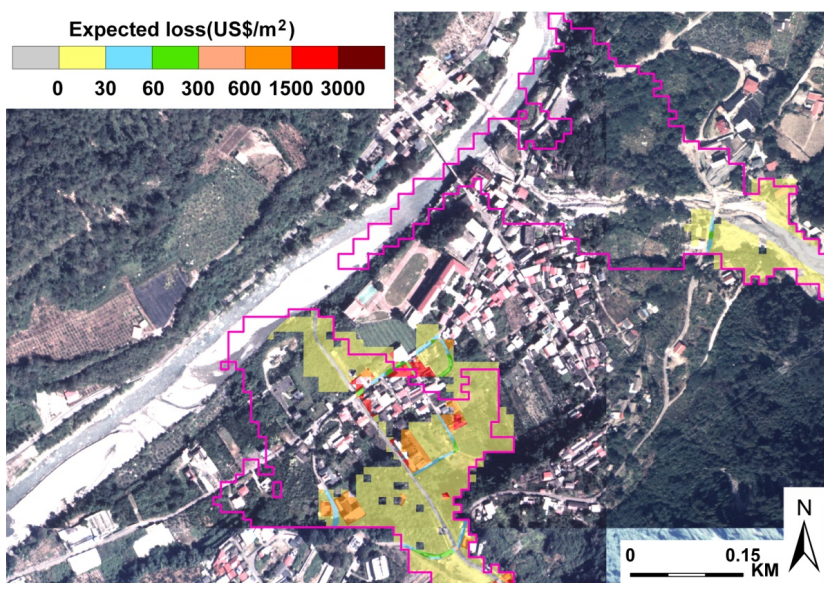

Fig. 8. Map showing the expected total loss caused by debris flows of the Nos. 1 and 2 Torrents for an event with 50-year return period after mitigation structures were installed and evacuation measures were implemented. The pink line is the boundary of the simulated debris flow deposits in Fig. 2.

to $\$ 0.36$ million from $\$ 1.22$ million for the No. 2 Torrent. The delimitation of the Designated Soil and Water Conservation Area avoids possible losses incurred during community development. If the restrained expansion strategy was not implemented, buildable land in hazardous areas may have been developed as buildings. When all buildable land was developed as houses, the spatial distributions of maximum expected total loss were as showed in Fig. 9, and the total annual risks $\left(R_{\text {total }}\right)$ increased to $\$ 0.78$ million from $\$ 0.72$ million for the No. 1 Torrent and to $\$ 2.21$ million from $\$ 1.22$ million for the No. 2 Torrent.

\subsection{Benefit-cost analysis of the reduction program}

Total annual risks were analyzed for the following scenarios: no mitigation structures and no evacuation measures; mitigation structures alone; evacuation measures alone; and mitigation structures with evacuation measures. The results are shown in Table 6.

Total primary cost of mitigation structures and evacuation measures in the Songhe community are shown in Table 5 (SWCB, 2006). Interest rate $(i)$ was set at 0.06 according to the common use of watershed comprehensive treatment programs in Taiwan (Huang, 1992; Chou, 1998; Shen, 2006; Taipei Water Management Office, 2006; Soil and Water Conservation Bureau, 2006). The life term $(n)$ of mitigation structures was defined as 10 years because of the severe and highly frequent debris flow disasters in Taiwan, and the life term of the evacuation measures taken as five years because of the decreases of disaster prevention awareness of residents over time. The annual cost of mitigation structures can be calculated for each torrent. However, because

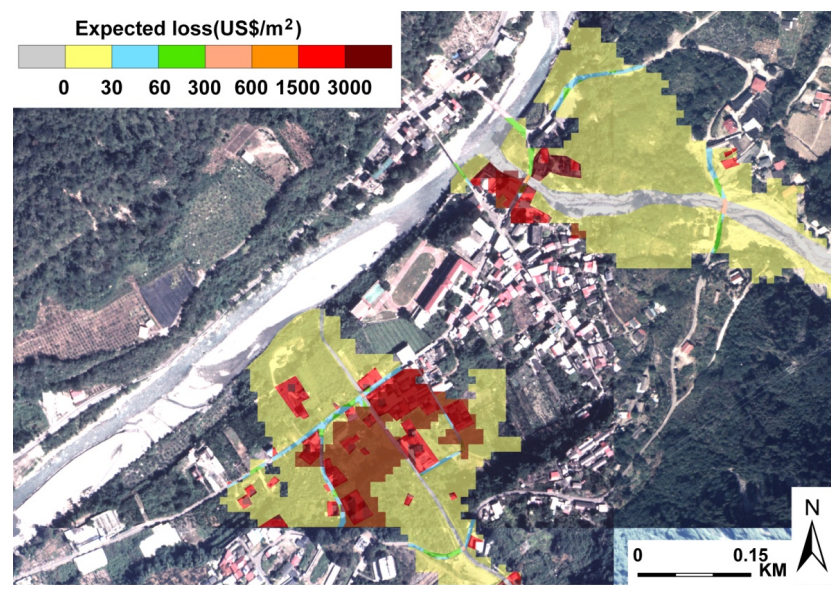

Fig. 9. Map showing the maximum expected total loss caused by debris flows of the Nos. 1 and 2 Torrents for an event with 50-year return period when the delimitation strategy was not conducted.

evacuation education and training plans in the Songhe community were provided to residents in the entire area, the costs were separated for residents affected by the Nos. 1 and 2 Torrents. Thus, the total costs and benefits of the evacuation measures for the entire area were calculated using benefitcost analysis. Notably, the primary cost of evacuation measures does not include the self-incurred evacuation costs of residents shown in Table 5. A real-time monitoring system consisting of cameras and a rain gauge was installed to monitor the torrents. Professional debris-flow volunteers were trained to provide debris-flow warnings to residents and to strengthen the self-rescue ability of the community. Training and equipment expenses were on average $\$ 746$ per volunteer. Total expenditure for the evacuation measures was about $\$ 0.12$ million as shown in Table 5 (SWCB, 2007). The annual cost of the evacuation measures was calculated for the entire area (Table 6).

The benefit-cost ratios for mitigation structures and evacuation measures in the Songhe community were calculated. The benefit-cost ratio for mitigation structures exceeded 1 for both torrents with an average of 3.87 (Table 6), indicating that the mitigation structures installed were cost-efficient. The benefit-cost ratio of evacuation measures markedly exceeded 1.0, indicating that the evacuation measures were highly beneficial. Mitigation structures require large investments but are capable of reducing the size of hazard zones; conversely, evacuation measures cannot reduce the size of hazard zones but are effective in increasing the resilient capacity of residents. Combining mitigation structures and evacuation measures enhances the benefit with a benefit-cost ratio of 4.38 . 


\section{Conclusions}

Specifically, the risk assessment method, delineating the hazard zones and analyzing the expected losses and resilient capacity of an affected community, can be used to calculate the expected property, life, and total losses and the corresponding risks. Firstly, peak discharges of debris flows were calculated based on the rational formula. Sediment deposition depths were then simulated using the FLO-2D model and the results were used to delineate hazard zones. Secondly, the expected property and life losses were analyzed. The land-use layer was developed by dividing the affected area into element types, including house, farmland, forestland, road, bridge, and river. It was then overlaid with the hazard zone layer to calculate the values of individual elements at risk. The damage factor of an element, defined as the ratio of actual loss to the value of the element, was used to analyze vulnerability of the element. Expected property losses were calculated using the values of elements and damage factors, whereas expected life losses were calculated using life value, damage factor, and vulnerability of residents in buildings. Thirdly, the resilient capacity of community, measured by "Resident Capacity" and "Community Resources," was estimated using data collected from resident questionnaires and community checklists. Expected property and life losses for individual hazard zones were then calculated and the distribution maps were plotted. Frequency curves for expected losses were established for assessing the annual risks. The proposed method was successfully applied to the Songhe community to assess debris flow risks and to evaluate the performance of the risk reduction program, including mitigation structures, evacuation measures and community restrained expansion strategy. Total annual risk decreased to $\$ 0.01$ million from $\$ 0.72$ million for the No. 1 Torrent and to $\$ 0.36$ million from $\$ 1.22$ million for the No. 2 Torrent after mitigation structures were installed and evacuation measures were implemented. The benefit-cost ratios of mitigation structures for both torrents were found to be greater than 1.0, indicating that the measures were cost-effective. The benefit-cost ratio of the evacuation measures for the entire affected area was markedly greater than 1.0 , indicating that the measures were highly beneficial. Mitigation structures require considerable investment but can reduce the size of hazard zones; so the expected property losses and expected life losses decreased simultaneously. The delimitation of the Designated Soil and Water Conservation Area restrained community expansion and decreased possible losses. Evacuation measures were not capable of reducing the size of hazard zones but were effective in increasing the resilient capacity of residents. The evacuation measures used in Taiwan such as the early warning system and professional debris-flow volunteers can also be used worldwide. The risk reduction program for a community, consisting of a combination of mitigation structures and evacuation measures based on restrained expansion, further enhanced benefits with a benefitcost ratio of 4.38 .

Acknowledgements. The authors would like to thank the Soil and Water Conservation Bureau (SWCB), Council of Agriculture, Taiwan, for financially supporting this research. The Branches of the SWCB and involved counties, towns, and communities are commended for their full cooperation. The local residents are also thanked for their opinions and suggestions.

Edited by: K.-T. Chang

Reviewed by: S. Fuchs and another anonymous referee

\section{References}

Agriculture and Food Agency, Council of Agriculture: Agricultural Situation Investigation Search, available at: http://agr.afa.gov.tw/ afa/afa_DFame.jsp, last access: 10 July 2006 (in Chinese).

Agriculture and Food Agency, Council of Agriculture: Agricultural Products Price Search System, available at: http://apis.afa.gov. tw:8000/agrPR-net/index.htm, last access: 10 July 2006 (in Chinese).

Bell, R. and Glade, T.: Quantitative risk analysis for landslides - Examples from Bíldudalur, NW-Iceland, Nat. Hazards Earth Syst. Sci., 4, 117-131, doi:10.5194/nhess-4-117-2004, 2004.

Bertolo, P. and Wieczorek, G. F.: Calibration of numerical models for small debris flows in Yosemite Valley, California, USA, Nat. Hazards Earth Syst. Sci., 5, 993-1001, doi:10.5194/nhess-5-9932005, 2005.

Cardinali, M., Reichenbach, P., Guzzetti, F., Ardizzone, F., Antonini, G., Galli, M., Cacciano, M., Castellani, M., and Salvati, P.: A geomorphological approach to the estimation of landslide hazards and risks in Umbria, Central Italy, Nat. Hazards Earth Syst. Sci., 2, 57-72, doi:10.5194/nhess-2-57-2002, 2002.

Chen, S. C., Wu, C. H., Ko, Y. C., Ferng, J. W., and Wu, C. Y.: The New Concept of Risk Identification and Management Strategies for Disaster Resistant Communities, Proceedings of Conference on Sustained Soil Conservation and Rural Development, Taipei, Taiwan, 265-282, 2005 (in Chinese with an English abstract).

Chen, S. C. and Wu, C. H.: Slope stabilization and landslide size on Mt. 99 Peaks after Chichi Earthquake in Taiwan, Environ. Geol., 50, 623-636, 2006.

Chen, S. C., Wu, C. Y., and Wu, T. Y.: Resilient capacity assessment for geological failure areas - examples from communities affected by debris flow disaster, Environ. Geol., 56, 1523-1532, 2009.

Chou, H. C.: Economic Evaluation of the Fourth Integrated Management Planning for the Techi Reservoir Watershed, Master thesis, National Chung-Hsing University, Taiwan, 1998 (in Chinese).

Construction and Planning Agency, Ministry of Interior: Non-City Land Development Influenced Value List, available at: http: //www.cpami.gov.tw/pwi/rp/rp_20.php, last access: 15 February 2007 (in Chinese).

Deyle, R. E., DFench, S. P., Olshansky, R. B., and Paterson, R. G.: Hazard assessment: The factual basis for planning and mitigation, in: Cooperating with Nature: Confronting Natural Hazards 
with Land-Use Planning for Sustainable Communities, Joseph Henry Press, Washington, DC, 119-166, 1998.

ESRI: ArcView users manual, version 3, Dallas, Texas, USA, 2002.

Fiebiger, G.: Hazard mapping in Austria, Journal of Torrent, Avalanche, Landslide and Rockfall Mitigation structures, 134(61), 153-164, 1997 (also in English and German).

FLO-2D: Users manual, Version 2003.06, Nutrioso, Arizona, USA, 2003.

Forestry Bureau, Council of Agriculture: Forest Disaster Statistics System - Forest Disaster Monthly Publication in Taiwan, available at: http://statistics.forest.gov.tw/for89-1a/, last access: 10 July 2006 (in Chinese).

Forte, F., Pennetta, L., and Strobl, R. O.: Historic records and GIS applications for flood risk analysis in the Salento peninsula (southern Italy), Nat. Hazards Earth Syst. Sci., 5, 833-844, doi:10.5194/nhess-5-833-2005, 2005.

Fuchs, S., Heiss, K., and Hübl, J.: Towards an empirical vulnerability function for use in debris flow risk assessment, Nat. Hazards Earth Syst. Sci., 7, 495-506, doi:10.5194/nhess-7-4952007, 2007a.

Fuchs, S., Thöni, M., McAlpin, M. C., Gruber, U., and Bründl, M.: Avalanche hazard mitigation strategies assessed by cost effectiveness analyses and cost benefit analyses - evidence from Davos, Switzerland, Nat. Hazards, 41, 113-129, 2007b.

Groot, W., Maassen van den Brink, H., and Plug, E.: Money for health: the equivalent variation of cardiovascular diseases, Health Econ., 13(9), 859-872, 2004.

Heping Township Household Registration office, Taichung County: Every Household Members Statistics, 2007.

Huang, J. H.: Wu-Sheh Reservoir's Watershed Management for Protection and its Economic Analysis, Master thesis, National Chung-Hsing University, Taiwan, 1992 (in Chinese).

Huggel, C., Kääb, A., and Salzmann, N.: Evaluation of quickbird and ikonos imagery for assessment of high-mountain hazards, EARSeL eProceedings, 5, 56-67, 2006.

ISDR: Living with Risk: A Global Review of Disaster Reduction Initiatives, United Nations ISDR, Geneva, 2002.

Liu, K. F. and Li, H. C.: The Study of the Direct Damage Estimation of Debris Flow, Journal of Chinese Soil and Water Conservation, 37(2), 143-155, 2006 (in Chinese with an English abstract).

Liu, X. and Lei, J.: A method for assessing regional debris flow risk: an application in Zhaotong of Yunnan province (SW China), Geomorphology, 52, 181-191, 2003.

Liu, X. and Mo, D.: Risk Assessment on Debris Flow, Chengtu, China, ISBN: 7-5372-3567-8, 2003.

O'Brien, J., Julien, P., and Fullerton, W.: Two-dimensional water flood and mudflow simulation, J. Hydraul. Eng., 119, 244-261, 1993.

Peter, Z.: Natural catastrophes and reinsurance, Swiss Reinsurance Company, Switzerland, 2003.

Pilgrim, D. H. and Cordery, I.: Flood Runoff, in: Handbook of Hydrology, edited by: Maidment, D. R., McGraw-Hill, Inc., 9.149.17, 1993.

Remondo, J., Bonachea, J., and Cendrero, A.: Quantitative landslide risk assessment and mapping on the basis of recent occurrences, Geomorphology, 94, 496-507, 2008.
Rickenmann, D.: Methoden zur Gefharenbeurteilung von Murgängen, in: Project CADANAV Etablissement d'une méthodologie de mise en oeuvre des cartes de dangers naturels du Canton de Vaud, 2ème rapport intermédiaire, Ecole Polytechinique Fédéral de Lausanne, Switzerland, 2001 (in German).

Shen, W. T.: Water Quality Clarity of Jing-Mian Reservoir by EcoEngineering Method, Master thesis, National Cheng Kung University, Taiwan, 2006 (in Chinese).

Soil and Water Conservation Bureau: Debris Flow Disaster Prevention Preparedness and Management System, http://210.69.127. 223, last access: 15 February 2007 (in Chinese).

Soil and Water Conservation Bureau: Integrated Management Planning for Shihmen Reservoir and its Watershed - Watershed Conservaion Planning of first step from 2006 to 2008, 2006 (in Chinese).

Soil and Water Conservation Bureau: Investigation on Vulnerability Factors and Planning Strategies of Debris-flow Danger Villages, appendix H-3, 2006.

Soil and Water Conservation Bureau: The Report of Integrated Planning for Debris Flow Disaster in Songhe Community, Taichung County, Taiwan, Council of Agriculture, 2005.

Taichung County Revenue Agency: Taichung County House Standard Unit Price List, available at: http://www.tcftax.gov.tw/, last access: 15 February 2007 (in Chinese).

Taipei Water Management Office: Investigation, Planning and Design of Watershed Engineering Practices for Taipei Water Source Domain, 2006 (in Chinese).

Tang, C. and Okimura, T.: Integrated Assessment of Urban Debris Flow Hazards Using RS/GIS: A Case Study of Dongchuan Urban Area, Kunming City, China, J. Geogr. Sci., 44, 1-22, 2006.

Team KNU: Richtlinien für die Wirtschaftlichkeitsuntersuchung und Priorisierung von Maßnahmen der Wildbach- und Lawinenverbauung, Federal Ministry for Agriculture, Forestry, Environment and Water Management, Austria, 2005 (in German).

Tobin, G. A. and Montz, B. E.: Natural Hazards: Explanation and Integration, Guilford Publishing, New York, 1997.

United Nations, Department of Humanitarian Affairs: Mitigating Natural Disasters: Phenomena, Effects and Options - A Manual for Policy Makers and Planners, United Nations, New York, 164 pp., 1991.

Wang, Y. T.: Establishing an Assessment Model for the Resilient Capacity of Slopeland Communities - for Taichung and Nantou Counties, Master thesis, National Chung-Hsing University, Taiwan, 2005 (in Chinese).

Wu, C. H. and Chen, S. C.: Determining landslide susceptibility in Central Taiwan from rainfall and six site factors using the analytical hierarchy process method, Geomorphology, 112(3-4), 190204, doi:10.1016/j.geomorph.2009.06.002, 2009.

Wu, T. Y.: Assessment of Resilient Capacity for Debris Flow Disasters Communities, Master thesis, National Chung-Hsing University, Taiwan, 2006 (in Chinese).

Zêzere, J. L., Oliveira, S. C., Garcia, R. A. C., and Reis, E.: Landslide risk analysis in the area North of Lisbon (Portugal): evaluation of direct and indirect costs resulting from a motorway disruption by slope movements, Landslides, 4, 123-136, 2007. 